\title{
Esofagitis inducida por tetraciclinas
}

\section{Tetracycline-induced esophagitis}

\author{
Henry Alberto Royero-Gutiérrez • Ocaña (Colombia) \\ Wendy Paola Ahumada-Rodríguez • Barranguilla (Colombia)
}
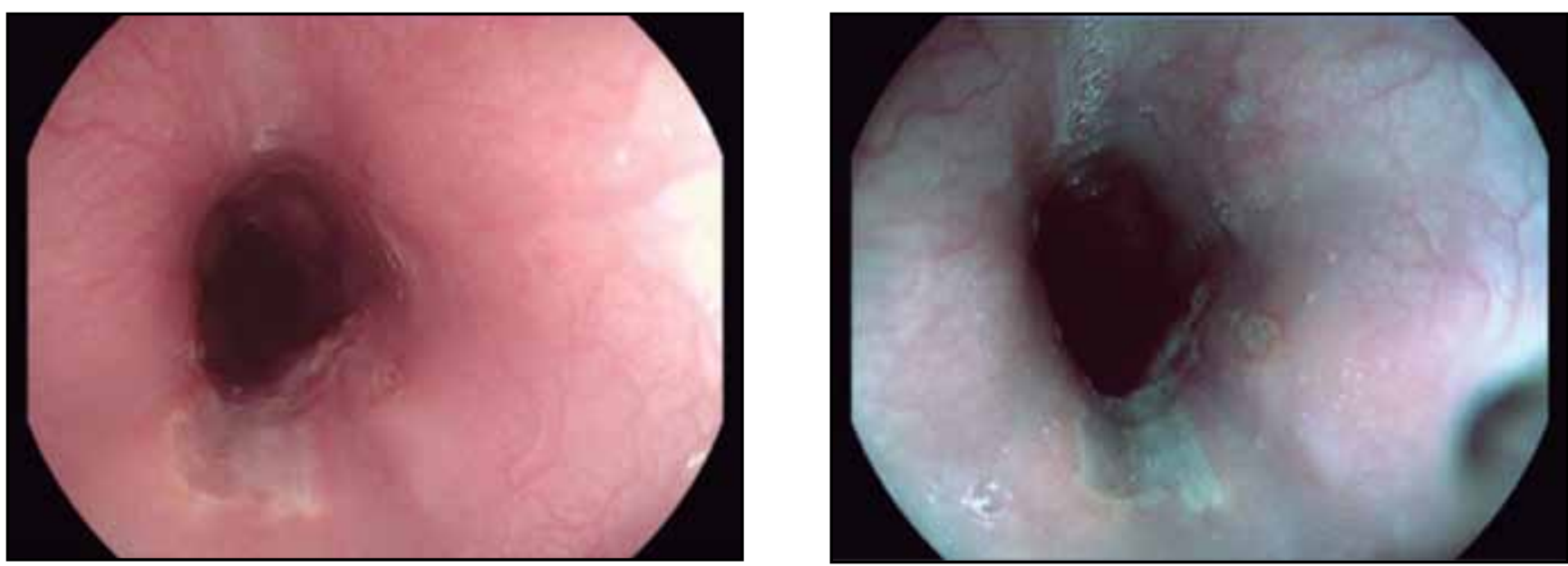

Figura 1. Endoscopia digestiva alta con luz blanca. Pentax i-scan, lesiones ulceradas en tercio medio esofágico, con mucosa adyacente respetada. La misma lesión observada con cromoendoscopia digital.

Masculino de 16 años, quien consultó por dolor torácico retroesternal de 72 horas de evolución, exacerbado por ingesta de alimentos. El dolor fue gradual hasta percibirlo con intensidad de $9 / 10$, se irradiaba a espalda y hombro derecho. Ingería doxiciclina para el acné, acostándose la mayoría de las veces después de consumirlas. Se indicó endoscopia de vías digestivas altas (EVDA), observándose lesiones ulceradas en tercio medio esofágico con mucosa adyacente respetada (Figura 1); se inició acetaminofén más tramadol como analgésico. Quince días después cursó asintomático y la EVDA encontró el esófago sano (Figura 2). El diagnóstico de esofagitis inducida por medicamentos puede ser hecho por la historia clínica, la EVDA debe indicarse en pacientes que presentan síntomas severos, signos de alarma o persistencia de éstos una semana después de suspender el medicamento. En la mayoría de casos la esofagitis por tetraciclinas mejora en pocos días sin ninguna intervención $(1,2)$.

\section{Referencias}

1. Rottenstreich M, Rottentreich M,Shapira S. Doxycycline induced esophageal ulcers in a navy ships crewmember. Int Marit Health. 2015; 66: 181-183.

2. Dag M, Oz Turk Z, Tutar E, Cikman O, Gulsen M. Drug-Induced esophageal ulcers: Care series and review of the literature. Turk J Gastroenterol. 2014; 25: 180-184.

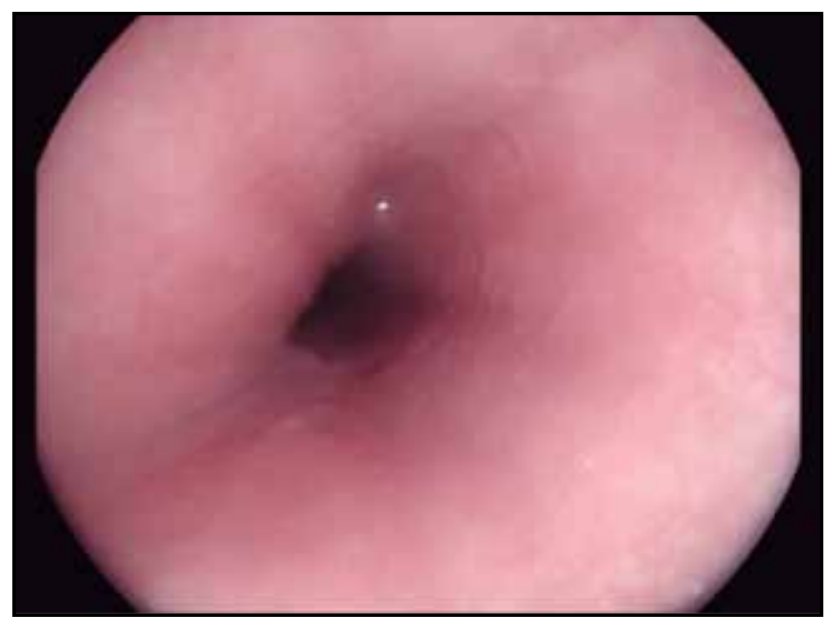

Figura 2. Endoscopia digestiva alta con luz blanca, 15 días después con esófago sano.

Dr. Henry Alberto Royero-Gutiérrez: Especialista en Medicina Interna y Gastroenterología, Hospital Emiro Quintero Cañizares. Ocaña (Colombia); Dra. Wendy Paola AhumadaRodríguez: Médica Interna, Universidad Metropolitana. Barranquilla (Colombia).

Correspondencia: Dr. Henry Alberto Royero-Gutiérrez, Ocaña (Colombia).

E-mail: royerogastro@hotmail.com

Recibido: 28/X/2017 Aceptado: 23/X/2018 